\title{
Educational factors that influence the urban-rural distribution of health professionals in South Africa: A case-control study
}

\author{
S J Reid, I D Couper, J Volmink
}

Setting. The influence of undergraduate and postgraduate training on health professionals' career choices in favour of rural and underserved communities has not been clearly demonstrated in resourceconstrained settings.

Objectives. This study aimed to evaluate the influence of educational factors on the choice of rural or urban sites of practice of health professionals in South Africa.

Methods. Responses to a questionnaire on undergraduate and postgraduate educational experiences by 174 medical practitioners in rural public practice were compared with those from 142 urban public hospital doctors. Outcomes measured included specific undergraduate and postgraduate educational experiences, and noneducational factors such as family and community influences that were likely to affect the choice of the site of practice.

Results. Compared with urban doctors, rural respondents were significantly less experienced, more likely to be black, and felt significantly more accountable to the community that they served. They were more than twice as likely as the urban group to have been exposed to rural situations during their undergraduate training, and were also five times more likely than urban respondents to state that exposure to rural practice as an undergraduate had influenced their choice of where they practise. Urban respondents were significantly more attracted to working where they do by professional development and postgraduate education opportunities and family factors than the rural group.

Conclusions. Evidence is provided that rural exposure influences the choice of practice site by health professionals in a developing country context, but the precise curricular elements that have the most effect deserve further research.

S Afr Med J 2011; 101: 29-33.
Among factors that influence health professionals' career choices in favour of rural and under-served communities, the role of undergraduate and postgraduate training is assumed to be significant. ${ }^{1-3}$ Selection criteria for entry to training, timing, duration, site and type of exposure to educational opportunities in rural and underserved areas during the undergraduate phase, and the availability of postgraduate programmes that support rural practitioners, all influence the decisions of health science graduates regarding their site of practice. ${ }^{4}$ However, the extent of this influence has not been assessed in resource-constrained settings, and the applicability of international studies in South Africa has been questioned. While a correlation between medical students' rural origin and practice in rural areas after qualification has been established, ${ }^{5-11}$ the evidence for the influence of exposure to community-based and rural placements during undergraduate training is less conclusive.

Most medical schools in South Africa have carried out major revisions of undergraduate medical curricula, some towards a 5 -year degree. Four universities identified the need for attention to rural health, and appointed senior academics to pilot new programmes in this area at undergraduate and postgraduate levels. Three universities have established specific rural sites for training health science students in this field. A study of innovative curricula

Primary Health Care Directorate, Faculty of Health Sciences, University of Cape Town S J Reid, BSc (Med), MB ChB, MFamMed

Division of Rural Health, Department of Family Medicine, University of the Witwatersrand, Johannesburg

I D Couper, BA, MB BCh, MFamMed, FCFP (SA)

Deputy Dean: Research, Faculty of Health Sciences, Stellenbosch University, Tygerberg, W Cape

J Volmink, BSc, MB ChB, DCH, MPH, DPhil (Oxon) and student support programmes at South African medical schools in 2000 found that all schools had introduced selection criteria and academic support mechanisms to facilitate access for historically disadvantaged students. ${ }^{12}$ Two schools included in this study had also deliberately moved away from hospital-based towards communitybased education.

The Collaboration for Health Equity in Education and Research (CHEER) ${ }^{13}$ asked academics involved in community-based education or rural health from each of the eight universities in South Africa with a health science faculty to declare the principles and assumptions underpinning their work for scrutiny and debate. While everyone believed that getting students out of urban tertiary hospitals and into rural and under-served areas is important in their education, there was little evidence that this influences students' choices of where they practise once qualified. Views also differed within the group regarding the most effective educational strategies for influencing graduates' choice of practice location.

We aimed to evaluate the extent to which educational factors influenced health professionals' choice to practise in rural or urban sites in South Africa.

\section{Methods \\ Study design}

We focused on medical practitioners as the largest single category of health professionals trained in faculties of health science. The study included all registered medical practitioners working at public hospitals who had completed their undergraduate medical education at a South African medical school, and who were not interns, community service medical officers or registrars (residents).

Medical practitioners holding part-time or sessional posts in the public service, whether also in private practice or not, were included, since they contribute to the public sector to some degree.

To assess the influence of educational exposure we chose a casecontrol study design with cases defined as rural medical practitioners and controls being urban medical practitioners working in the South African public service. We compared the frequencies of several educational exposures in cases and control groups, adjusting for 
potential confounding factors. The educational factors measured included community-based experiences in the curriculum, exposure to a rural situation as an undergraduate, professional and career development, and extra-curricular learning experiences. Potential confounding factors were race, gender, time since graduation, experiences at high school, family issues, financial issues, role models, and a sense of accountability to the community.

\section{Sample}

Based on our assumption of a $50 \%$ exposure of controls to a positive community-based or rural experience during their training, we calculated that a sample size of 150 cases and 150 controls would detect an odds ratio (OR) of 2 or greater with $80 \%$ power and at a significance level of $5 \%$. Since cases were distributed in small numbers in rural hospitals across the country, a lower response rate of $50 \%$ from the rural cases was anticipated than from the controls, who were more accessible, so more cases were sampled to reach the desired minimum of 150 .

\section{Identification of cases and controls}

Cases were identified by whether they receive the rural allowance at their designated hospitals, according to the South African Department of Health gazetted list. ${ }^{14}$ Letters of introduction were sent to the hospital managers, medical superintendents or chief executive officers of all 143 hospitals designated for the rural allowance, requesting permission to conduct the study, authorisation to contact doctors in their hospitals, and assistance in identifying all South African-trained doctors in their hospitals, excluding interns, community service doctors and registrars.

The controls were identified as doctors working in public hospitals in major metropolitan areas and who did not receive a rural allowance. We took a random sample of 11 urban hospitals from a total list of 25 using a table of random numbers and wrote to the senior manager at each hospital requesting the names of each South African-qualified doctor on the staff, excluding interns, community service officers and registrars. Large hospitals delegated this task to heads of departments who identified potential respondents.

\section{Data collection and analysis}

A structured questionnaire was used based on a previous qualitative study ${ }^{15}$ in which 15 rural health professionals and 11 urban-based practitioners were interviewed to determine how and why they chose the site of their current practice. The questionnaire was piloted with 5 medical practitioners in Durban and adjusted accordingly; the final version was mailed to participants in self-addressed, stamped envelopes. Respondents were assured of anonymity. Ethics approval was obtained from the University of KwaZulu-Natal Bioethics Research Committee, reference number E091/05.

To maximise the response rate and obtain their written consent to participate, cases and controls were telephoned after we sent the questionnaire to them. Participants were asked to return the signed consent form and the completed questionnaire by fax to a research assistant. Those who did not respond were followed up, initially through their managers and later by telephone individually. The assistant visited each major metropolitan area in turn to follow up non-responding controls, and rural respondents were followed up repeatedly by telephone until a sufficient number of cases and controls was obtained.

The data were entered and analysed in SPSS. Differences in the distribution of individual factors among cases and controls were assessed using the chi-square test for dichotomous variables and the $t$-test for continuous variables. We used the odds ratio ( $95 \%$ confidence interval (CI)) to estimate the effect size associated with various factors. A multivariate logistic regression model determined which educational factors remained significantly associated with practice location after controlling for potential confounders.

\section{Results}

A total of 682 questionnaires were distributed to 432 cases and 250 controls. A total of 342 responses were received (overall $50 \%$ response rate), of which 26 were excluded as they did not meet the selection criteria for cases or controls (e.g. respondents qualified outside South Africa); 174 were cases (41\% response) and 142 controls (57\% response), drawn from 136 rural hospitals and 11 urban hospitals, respectively. There were no South African-trained doctors at 5 hospitals, and no response was obtained from 2. Two-thirds of respondents were male, with the same proportions in the rural and urban groups. A significantly greater proportion of black doctors were in the rural group (59\%) than the urban group (8\%). Half of all respondents were married, with more unmarried in the rural group, but this was not statistically significant (Table I).

Respondents were from all 9 provinces and 8 universities. Gauteng province was proportionately under-represented in the control group. Graduates from the University of the Witwatersrand, Johannesburg, and Walter Sisulu University, (formerly University of Transkei), Mthatha, were under-represented in terms of the universities from which both cases and controls qualified. Twenty-two per cent of rural and $25 \%$ of urban respondents were in private practice in addition to their public service positions (not statistically significant). Thirty of the 174 rural respondents did not receive the rural allowance, as they held part-time posts or sessions in the hospitals; only full-time state employees in designated hospitals receive the allowance.

Mean length of time since qualification was significantly different for the two groups, being 9.1 years for the rural group (cases) as opposed to 17.5 years for the urban group (controls). Almost all of the controls (96\%) had spent most of their career at regional tertiary and specialised hospitals, whereas the majority of the cases (56\%) had spent most of their careers at district hospitals; this difference was significant.

Table I. Descriptive characteristics of respondents

\begin{tabular}{lllll}
\hline & All $(N=316)$ & Rural cases $(N=174)$ & Urban controls $(N=142)$ & $p$-value \\
\hline Male gender (\% (95\% CI)) & 66 & $68(61-75)$ & $65(56-72 \%)$ & 0.80 \\
Married (\% (95\% CI)) & 50 & $48(41-55)$ & $53(45-61 \%)$ & 0.12 \\
Black $\%(95 \% \mathrm{CI}))$ & 36 & $59(51-66)$ & $8(4-13 \%)$ & $<0.05$ \\
White \& other (\% (95\% CI)) & 63 & $30(24-38)$ & $78(70-83 \%)$ & $<0.05$ \\
Average time since qualification (yrs) & 13.3 & 9.1 & $25(19-33 \%)$ & 0.56 \\
Private practice (\% (95\% CI)) & 25 & $22(17-29)$ & \\
\hline
\end{tabular}




\section{Educational factors influencing practice location}

Table II shows the educational and non-educational factors that influenced respondents' choices with regard to site of practice, arranged by the size of the effect (OR); $37 \%$ stated that experiences at high school (not defined) were important, rural respondents rating these significantly higher than urban respondents; $38 \%$ said that their undergraduate medical experiences played a role; and $46 \%$ said that they were influenced more by extra-curricular experiences than those within the curriculum. Rural and urban respondents did not differ significantly in these respects. Eighty-one per cent of respondents were exposed first-hand to community-based health care outside a hospital or clinic as a medical student, and $82 \%$ of these experiences occurred from 4th year onwards - in this regard there was no significant difference between cases and controls.

Most respondents (71\%) were exposed to a rural situation as an undergraduate within the curriculum, and most of these were in the latter years. On univariate analysis, significantly more rural respondents than urban respondents reported this exposure (OR 2.4, $p<0.05)$. Significantly more rural than urban respondents reported that their experiences as undergraduates of community-based health care (OR 2.7, $p<0.05)$ and rural situations (OR 5.1, $p<0.05)$, influenced their decision to practise where they do. Rural respondents also stated that their rural experiences as undergraduates were meaningful and enjoyable, significantly more than the controls $(p<0.05)$. Furthermore, rural respondents rated their sense of accountability to the communities that they serve significantly higher than the urban controls (OR 1.9, $p<0.05)$. Most respondents rated professional and career development (61\%), family ( $80 \%)$ and financial issues (58\%) as important considerations in deciding where to practise. Significantly more urban respondents rated professional and career development and family issues higher than rural respondents $(p<0.05)$ as reasons for choosing to practise where they do. Urban respondents also rated experiences as postgraduate students significantly higher than rural respondents in deciding where to practise $(p<0.05)$. Of all respondents, 30 - 40\% rated specific individuals whom they had found inspirational while they were medical students or after qualifying as influencing their decisions, with no significant differences between cases and controls.

Upon controlling for all other variables by multivariate logistic regression, only race, years of experience since qualification, and whether the rural exposure reportedly influenced the choice of site of practice, remained significant predictors of rural practice site (Tables III and IV).

\section{Discussion}

Cases and controls differed significantly in their responses to questions about whether community-based and rural experiences in the undergraduate curriculum had influenced their choice of practice. Rural respondents were more than twice as likely to report having been exposed to rural situations during their undergraduate training than the urban group, and five times more likely than urban respondents to state that exposure to rural practice as an undergraduate had influenced their choice of where they practise. The latter remained significant when all other variables were controlled. These results are similar to those in Australia. ${ }^{16}$ In contrast, a study in Canada ${ }^{17}$ found no significant difference between physicians exposed to rural practice during undergraduate training and those who were not, in respect of their choice of a rural practice location. At the University of Transkei,

Table II. Factors influencing respondents' choices of site of practice, showing uncontrolled odds ratios and significance between cases and controls

\begin{tabular}{|c|c|c|c|c|c|}
\hline Influencing factor & All $(N=316)(\%)$ & $\begin{array}{c}\text { Rural cases } \\
(N=174)(\%)\end{array}$ & $\begin{array}{l}\text { Urban controls } \\
(N=142)(\%)\end{array}$ & OR $(95 \% \mathrm{CI})$ & $p$-value \\
\hline \multicolumn{6}{|c|}{ 1. Significant difference between rural and urban, with rural respondents more influenced by these factors than controls } \\
\hline Rural exposure influenced choice & 30 & 44 & 13 & $5.1(2.9-9.1)$ & $<0.05$ \\
\hline Community-based experience influenced choice & 32 & 41 & 20 & $2.7(1.6-4.5)$ & $<0.05$ \\
\hline Exposure to a rural situation as an undergraduate & 71 & 79 & 61 & $2.4(1.5-3.9)$ & $<0.05$ \\
\hline Sense of accountability to the community & 78 & 83 & 72 & $1.9(1.1-3.2)$ & $<0.05$ \\
\hline Experiences at high school & 37 & 43 & 29 & $1.9(1.1-3.1)$ & $<0.05$ \\
\hline Community-based experience early in curriculum & 18 & 20 & 15 & $1.4(0.8-2.5)$ & $<0.05$ \\
\hline \multicolumn{6}{|c|}{ 2. Significant difference between rural and urban, with urban respondents more influenced by these factors than rural } \\
\hline Family issues & 80 & 71 & 90 & $3.7(1.9-7.0)$ & $<0.05$ \\
\hline Professional and career development & 61 & 49 & 76 & $3.3(2.0-5.3)$ & $<0.05$ \\
\hline Experiences as a postgraduate student & 42 & 34 & 50 & $1.9(1.2-3.0)$ & $<0.05$ \\
\hline \multicolumn{6}{|c|}{ 3. No significant differences between rural and urban respondents } \\
\hline Financial issues & 58 & 61 & 53 & - & 0.27 \\
\hline Original motivation for studying medicine & 79 & 82 & 77 & - & 0.28 \\
\hline Specific individuals met after qualifying & 40 & 39 & 41 & - & 0.29 \\
\hline Overall experiences as an undergraduate student & 38 & 43 & 32 & - & 0.42 \\
\hline Exposure to community-based learning experiences & 81 & 83 & 79 & - & 0.63 \\
\hline Specific individuals met while a medical student & 30 & 28 & 32 & - & 0.86 \\
\hline Extra-curricular learning experiences & 46 & 49 & 43 & - & 0.92 \\
\hline
\end{tabular}


Table III. Factors significantly influencing respondents' choices regarding their site of practice, showing odds ratios and significant differences between cases and controls, when all other variables are controlled, by multivariate logistic regression

\begin{tabular}{lccc}
\hline Influencing factor & OR & $95 \%$ CI & $p$-value \\
\hline Family issues & 6.7 & $2.3-19.2$ & $<0.05$ \\
Race & 5.8 & $1.1-30.4$ & $<0.05$ \\
Rural exposure influenced & 3.4 & $1.0-12.0$ & $<0.05$ \\
choice & & & \\
Financial issues & 3.2 & $1.2-8.2$ & $<0.05$ \\
Years of experience & 1.1 & $1.0-1.1$ & 0.063 \\
\hline
\end{tabular}

Table IV. Factors significantly influencing respondents' choices regarding their site of practice, showing odds ratios and significant differences between cases and controls, when educational factors, race and years of experience are controlled

\begin{tabular}{lccc}
\hline Influencing factor & OR & $95 \%$ CI & $p$-value \\
\hline Race & 13.3 & $6.2-28.1$ & $<0.05$ \\
Rural exposure influenced choice & 3.7 & $1.6-8.5$ & $<0.05$ \\
Financial issues & 3.2 & $1.2-8.2$ & $<0.05$ \\
Years of experience & 1.0 & $1.0-1.1$ & $<0.05$ \\
\hline
\end{tabular}

South Africa, the stated preference for rural practice among medical students decreased from $48.5 \%$ in the first year of study to $5.9 \%$ in the final year, despite a community-based curriculum. ${ }^{18}$ Pathman ${ }^{19}$ suggests that we will not be able to measure the curriculum effect ('nurture') on future career choices properly unless we control for the pre-existing characteristics of the learners ('nature'), such as rural origin and a sense of social justice. When this was controlled for, Rosenblatt et al. found no association between students' participation in a family medicine course and their specialty selections. ${ }^{20}$

Demographically, the rural group had less experience and was more likely to have worked in district hospitals, including their community service year, than the urban controls. These findings could be anticipated because of the selection criteria for the cases and the controls, as rural areas are primarily served by district hospitals rather than regional and tertiary hospitals. That the rural cohort also had significantly fewer years of professional experience than those in urban public hospitals may indicate the rapid staff turnover in rural hospitals, and the phenomenon of urban drift of professionals. Professional development opportunities and other family factors in the cities, highlighted by the data, make the urban choice even more appealing - the so-called urban 'pull' factors and the rural areas 'push' factors. These results are not surprising, as practitioners seek opportunities to climb the professional career ladder in urban centres.

In South Africa, the findings that rural respondents were significantly more likely to be black could reflect the greater likelihood of graduates of rural origin returning to work in rural areas, as shown elsewhere. ${ }^{10}$ Social class, complicated by racial categories reflecting South Africa's history, was not tested in this study, but these findings suggest important avenues for future research. The sense of accountability to the communities that the rural practitioners serve was found to be significantly higher than in their urban counterparts, after controlling for confounders. This was evidenced in the preceding qualitative study, ${ }^{14}$ which found that personal values were of great importance in deciding to go into rural practice, and may reflect relative idealism at a younger age. From an economic perspective, the resource-poor public health system within a liberal market-driven economy gives South African doctors a wide freedom of choice regarding where they practise, since they are in high demand in the public and private sectors, and overseas. This finding indicates that socio-cultural factors often override financial considerations of where to practise in South Africa. Financial considerations showed no significant difference between rural and urban groups in deciding on the site of practice. It may also relate to the positive impact of the rural allowances in reducing dissatisfaction among rural doctors, ${ }^{21}$ or the lack of expectation of higher salaries by those remaining in the public sector compared with the private sector.

The sense of community and extended family accountability is relatively strong among black South African students, whose families often sacrifice materially for their medical student protégé to succeed. However, it has been assumed that as they progress through the curriculum they progressively lose these ties through the so-called 'hidden curriculum' and acquire more individualistic notions of career opportunities, as is indicated by findings of declining interest in rural practice. ${ }^{17}$ The high level of community accountability we found among younger rural practitioners relative to their older urban counterparts indicates that this factor is not lost after graduation, and may be more important in our context than we thought.

The degree of influence of specific educational interventions on career choice has been questioned, and the little evidence is contradictory. Although we did not control for pre-existing entry factors, the combined effect of selection policies and curricular interventions appeared to influence the choice of practice location. Controlling for all other factors, rural doctors were significantly more likely than urban doctors to report that rural exposure influenced their choice of practice site. This is reassuring, as it indicates that exposure to rural practice during training independently predicts that graduates will choose to practise in rural areas. Some of the control group, who ended up in urban practice, might have had negative experiences of rural practice during their undergraduate education, as indicated by rural respondents stating that their undergraduate rural experiences were significantly more meaningful and enjoyable than the controls. We know of no selection policies in operation in South Africa that advantaged students of rural origin, or those motivated to practise in rural or under-served areas by virtue of another factor, so this is unlikely to be a major confounding variable. In contrast, it is interesting to note that there was no difference between urban and rural respondents with regard to community-based exposure in the curriculum. It therefore seems that exposing students to communitybased health care will not influence them to practise in rural areas: only rural experience appears to have this effect.

Urban respondents rated professional and career development, family factors and experiences as postgraduate students much higher than rural respondents in influencing their choices. This is a common reason cited for moving from rural to urban practice, and points to the need for greater postgraduate training and career opportunities in rural areas, as indicated in other studies. ${ }^{21}$ This is more feasible in the era of information and communication technology than ever before. The overall experience as undergraduate students did not apparently influence their eventual site of practice, probably because any effect of a rural exposure was diluted by other experiences in the curriculum. Several potential biases may weaken the main results. There may have been some recall bias, in that the largely urban practitioners who did their undergraduate training 2 or 3 decades ago may not have recalled their motivations and decisions as clearly as the younger rural respondents. Medical curricula have also changed significantly over 
the past 30 years, in that community-based and rural components are a recent addition to most medical degree programmes. Older graduates, most of whom were in the control group, may not have had equivalent experiences within the curriculum. Also, rural respondents may have been more likely to recall their rural experience because it was more meaningful to them in the context of their current practice. Finally, a non-response bias is possible in that those who remembered their undergraduate experiences positively might have been more likely to return questionnaires than those who had negative experiences, leading to a more positive result than the reality.

While this study was limited by a small sample size, we believe the statistically significant difference between the two groups of the perceived role of rural exposure during undergraduate training strongly suggests that rural exposure is an important determinant of future practice in a rural public hospital in South Africa.

\section{Conclusion}

The maldistribution of human resources for health requires a multidimensional approach. Among the many factors that influence and determine health professionals' career choices, the educational component is held to be significant. Our study strengthens this view. These results provide evidence for the association of preceding undergraduate and postgraduate educational experiences with the choice of site of practice of doctors in South Africa. This supports the notion that exposing students to rural situations during their period of training is worthwhile, and deserves the extra resources that it demands as a strategy in addressing the problem.

Our thanks to the other members of the CHEER collaboration, the South African Department of Health, to the hospital managers, CEOs, medical managers and superintendents who participated, and to Equinet for funding to carry out the research. Special thanks to Flora Asah, research assistant, and her colleagues at the Centre for Rural Health of the University of KwaZulu-Natal. The authors declare that they have no conflicts of interest in publishing this study.

\section{References}

1. Dunbabin J, Levitt L. Rural origin and rural medical exposure: their impact on the rural and remote workforce in Australia. Rural Remote Health 2003;3 (online). http://rrh.deakin.edu.au/ (accessed 30 May 2008).

2. Pathman DE, Steiner BD, Jones MA, Thomas RK. Preparing and retaining rural physicians through medical education. Acad Med 1999;74(7):810-820.

3. Howe A, Ives G. Does community-based experience alter career preference? New evidence from a prospective longitudinal cohort study of undergraduate medical students. Med Educ 2001;35(4):391-397.

4. Wilson NW, Couper ID, De Vries E, Reid S, Fish T, Marais BJ. A critical review of interventions to redress the inequitable distribution of healthcare professionals to rural and remote areas. Rural Remote redress the inequitable distribution of healthcare professionals to rural
Health 2009; 9 (online). http://www.rrh.org.au (accessed 30 May 2008).

5. Cullison S, Reid C, Colwill JM. Medical school admissions, specialty selection, and distribution of Cullison S, Reid C, Colwill JM. Medical
physicians. JAMA 1976;235:502-505.

6. Carline JD, Cullen TJ, Dohner CW, et al. Career preferences of first- and second-year medical students: Carline JD, Cullen TJ, Dohner CW, et al. Career prefer
The WAMI experience. J Med Educ 1980;55:682-691.

7. Kamien M, Buttfield IH. Some solutions to the shortage of general practitioners in rural Australia. Part 1. Medical school selection. Med J Aust 1990;153:105-107.

8. Rabinowitz HK. Recruitment, retention, and follow-up of graduates of a program to increase the number of family physicians in rural and underserved areas. N Engl J Med 1993;328(13):934-939.

9. Rabinowitz HK, Diamond JJ, Markham FW, Hazelwood CE. A program to increase the number of family physicians in rural and underserved areas. Impact after 22 years. JAMA 1999;281(3):255-260.

10. Stearns JA, Stearns MA, Glasser M, Londo RA. Illinois RMED: A comprehensive program to improve the supply of rural family physicians. Fam Med 2000;32(1):17-21.

11. de Vries E, Reid S. Do South African rural origin medical students return to rural practice? S Afr Med J 2003;93(10):789-793.

12. Lehmann U, Andrews G, Sanders D. Change and Innovation at South African Medical Schools - an Investigation of Student Demographics, Students Support and Curriculum Innovation. Durban: Health Systems Trust, 2000

13. Reid SJ. A cheerful group: The collaboration for health equity through education and research (Editorial). South African Family Practice 2004;46(7):3.

14. Public Health and Welfare Service Coordinating Bargaining Council. Resolution No. 2 of 2004: Revised Non-Pensionable Recruitment Allowance, referred to as 'The Rural Allowance. Government Gazette 2004, Pretoria.

15. Couper ID, Hugo JFM, Conradie H, Mfenyana K. Influences on the choice of health professionals to practice in rural areas. S Afr Med J 2007;7:1082-1086.

16. Wilkinson D, Laven G, Pratt N, Beilby J. Impact of undergraduate and postgraduate rural training, and medical school entry criteria on rural practice among Australian general practitioners: national study of 2414 doctors. Med Educ 2003;37(9):809-814.

17. Easterbrook M, Godwin M, Wilson R, et al. Rural background and clinical rural rotations during medical training: effect on practice location. Can Med Assoc J 1999;160(8):1159-1163.

18. Dambisya YM. Career intentions of UNITRA medical students and their perceptions about the future. Educ Ha Y

19. Pathman DE. Medical education and physicians' career choices: Are we taking credit beyond our due? Acad Med 1996;71(9):963-968.

20. Rosenblatt RA, Alpert JJ. The effect of a course in Family Medicine on future career choice: a long-range follow-up of a controlled experiment in medical education. J Fam Pract 1979;8:87-91.

21. Reid S. Monitoring the Effect of the New Rural Allowance for Health Professionals. Durban: Health Systems Trust, 2004. http://www.hst.org.za/publications/643 (accessed 30 May 2008)

21. Kotzee TJ, Couper ID. What interventions do South African qualified doctors think will retain them in rural hospitals of the Limpopo province of South Africa? Rural Remote Health 2006;6 (online). http:// rrh.deakin.edu.au (accessed 30 May 2008).

Accepted 27 September 2010. 